\title{
Trust as catalyst for the organizational performance. A focus on a medium-size IT Romanian company
}

\author{
Raluca BADEA \\ badraluca@gmail.com \\ The Bucharest University of Economic Studies, Bucharest, Romania
}

\begin{abstract}
In an environment where the shift from knowledge to social economy forces the company to identify a new sustainable approach to attire, motivate and retain employees, partners and shareholders, social capital and its elements seem to be the key. The focus of the article is to prove the contribution that trust, in its entirety, as primary component of the social capital, has on the organizational performance of the company. The centric piece of the paper is based on a quantitative research conducted in a medium size IT company and it is designed to support the hypotheses per which a high level of trust will positively influence the overall business results. Regardless if it's societal trust, market trust, relationship trust or selftrust, the respondents are requested to assess its multiple dimensions as these are translated into the company's principles and values, the leaders' strategy to improve the life of the shareholders, the company's brands and their impact on the consumers, the relationship between individual and his/her peers and managers, as well as the individual's aspirational behavior to be a trusted colleague/employee. Analyzing the results of the questionnaire, trust as core element of the social capital appears to be a main factor that drives the competitive advantage, designed to boost the employees' energy, increase the sustainability for the company, irreversibly gain the confidence of stakeholders and eventually act a catalyst for the individual and organizational performance. The in-progress results of this paper represent significant key findings that trigger a more advance research, at a larger scale, by evaluating other companies, with similar employees' profile to confirm the magnitude of this influence and convince the business leaders to continue supporting the creation and leverage of social capital in general and strive to generate, build and maintain trust as a must have asset.
\end{abstract}

Keywords: trust, social capital, performance, organization, catalyst.

\section{Introduction}

As we evolve in a complex business environment, knowledge is no longer the ultimate competitive advantage. To stand out from the crowd and become acknowledged for one's expertise, other assets, such as emotional intelligence or social intelligence require to be activated and codified in the DNA of an individual and in the skeleton of a company.

Starting with social intelligence, which represents the ability of an individual to manage diverse and complex social relationships, the top companies, interested to leverage the organizational performance at its maximum, started to encourage and even mandate the adoption of social capital within their premises.

Social capital starts with each individual and his or her personal equity: who they are, what they are recognized for, what they stand for (principles and values). It continues with capability to build diverse, collaborative relationships with the peers, team members, partners, stakeholders so the individuals can benefit of and leverage the partners' know- 
how. Social capital is defined by a continuous cycle of share and reapply, give and take, where the individuals constantly need to update their mastery so they can take advantage of what the others in their network possesses. At the basis of all these, the catalyst which enables the interaction among groups and individuals is trust.

The present paper aims to conduct a short core literature analysis of the key topics in the field of social capital, by looking in depth at trust as its one of the basic components, as well as its characteristics and influencing factors.

Relying on the literature review, combined with direct observation insights, the paper proposes also a conceptual model, designed to define different types of trust as research variable and their dependency, as well the influence presence of trust in all its forms has on the individual performance, by highlighting the results of a research conducted within the premises of a medium size IT company.

\section{Literature review}

Despite its novelty in the economic field, social capital has quickly gained its share of popularity among scholars, almost with the same speed that social networks gained a significant amount of popularity among end users. Social capital was subject to different interpretations, by positioning its components as primary key identifiers. If for some authors, social capital represents "the sum of the actual and potential resources embedded within, available through, and derived from the network of relationships possessed by an individual or social unit" (Nahapiet and Ghoshal, 1998:243), other researchers focus on the social norms and values associated with relationships (e.g., Coleman, 1990; Putnam, 1993). Other definitions focus on the information channels and its broadcast in a free cost environment as a component of social capital, which generates values for the entrepreneurial activity. A similar dimension is recognized by Coleman who refers in his study to those actors interested to acquire some degree of knowledge in a certain domain, without being willing to pay for the information, reason for which they make use of the social relations, so that social capital becomes a public good (Coleman, 1994).

Trust, reciprocity, bridging and bonding relationship ties are additional components that define the social capital package, which once implemented and tracked down within an organization, can become a competitive advantage. Looking through one's lenses to the existing definitions acknowledged in the literature, social capital represents the sum of assets associated with one's social networks, where these assed are connected through common set of values and norms towards the individuals, organizations, stakeholders and shareholders and ultimately the society. (Paunescu, Badea, 2013)

The social capital created, maintained and implemented in a company can be defined as an intangible form of capital, resulted from the cumulus of the networks that are created within or outside the walls of the physical building and it is based on a relationship of trust and affiliation to a certain set of shared norms, values and principles. Even these components are generated collectively, it is highly encouraging that they would be used individually to innovate, grow and this way add value to the overall entrepreneurial activity of a company. Social capital is rooted in the strong and weak ties, internal and external connections created at individual level by each employee in the organization and at company level through the interaction with stakeholders and shareholders.

The presence of trust, as component of social capital becomes mandatory in the opinion of Dakhli and de Clercq (2004) who classify trust in generalized and 
institutionalized. This differentiation becomes extremely important when understanding that an organization is not a standalone entity, but this is performed in a complex environment, ruled by governmental laws and business policies. To be successful, an organization must embrace both the general trust, invested and expected at individual level and institutional trust, invested and expected from the relationship with the other organizations and institutions (Badea, 2013).

PICBE $\mid 772$

The levels of trust measured in the present research are the ones that Stephen Covey is also analyzing in his book "The Speed of Trust": self-trust, relationship trust, organizational trust, market trust and societal trust.

Self -trust represents the level of confidence one has in his/her ability to accomplish the objectives and goals and the reflection of his/her image to the others weather they are trust worthy persons. (Covey, 2006). There are four dimensions that define the self-trust that are also evaluated in the present questionnaire: the integrity, the intent, the capabilities and the results that can be aggregated by two main values: character and competence.

Relationship trust is related to the individual behavior and how the consistency of this behavior translates into the confidence his peers, colleagues and partners. It's about a mutual investment, where the trust dividends pay off at the maximum interest, however once betrayed will eventually lead to the bankruptcy of the partnership.

Organizational trust is the outcome of a powerful confidence between the individuals and the executive and middle management of an organization, both in their leadership principles, but also in the support provided to the employees.

Market trust is the most impactful one on the profitability of the company. It is the one that measures the confidence into the products, brands, reputation and image in front of the consumers, customers and shareholders.

Societal trust is the result of adapting the organizational culture to the specifics of the markets where the subsidiary of a company develops its business, by treating the Society as the most important stakeholder.

Combining the literature review with the personal direct observations, I can confirm that the interest in leveraging all the dimensions of trust as component of social capital seems to have increased significantly in the past years. Being aware on the benefits of bringing the outside in and the positive influence this has on both individual and organizational performance, the companies seem to encourage wherever possible the transfer of information and knowledge across teams, functions and departments and they're focused on building the trustworthy communication channels that would support these relations.

\section{Methodology}

The research has been conducted in a medium size IT company and it is required to test the hypotheses per which social capital through its components of trust has a direct influence on how an individual performs his/her job and how the results obtained in this job impacts positively the overal ogranizational performance and the equity that the company gains outside its premises.

The questionnaire is designed to measure the level of trust the individual has in everything that the company stands for. All five dimensions of trust: self-trust, relationship, organizational, market and societal trust represent the subject of the seventeen pairs of 
opposite statements included in the survey, designed to clearly highlight the confidence one has in the entire organizational environment, influenced by different actors: the shareholders, the managers, the peers, the brand and eventually, the individual himself. Throughout the interview, trust takes different forms, such that the respondent is requested to assess its multiple dimensions and this becomes in the end the baseline for his/her individual performance. Even though the questionnaire covers an abstract concept, I've intentionally chosen to address the same question twice, by using pairs of opposite statements and decrease as much as possible the biased answers.

The responded is requested to validate the following statements, highlighted in tables 1 and 2 and they are related to the five dimensions of trust, which are furthermore linked to hour hypothesis of this research.

Organizational Trust: Trust in the organization's values, principles and purpose, but also in the executive representatives of the organization in front of the individuals-middle and senior management.

Table 1. Validating Questions for the Organizational Trust

\begin{tabular}{|c|c|}
\hline $\begin{array}{c}\text { My company is based on a clear set of } \\
\text { principles and values. }\end{array}$ & $\begin{array}{c}\text { My company is exclusively focused on } \\
\text { getting the highest profit margins. }\end{array}$ \\
\hline $\begin{array}{c}\text { Trust is one of the key values promoted } \\
\text { within the company. }\end{array}$ & $\begin{array}{c}\text { I find it difficult to show any confidence } \\
\text { in the company's objectives and goals. }\end{array}$ \\
\hline $\begin{array}{c}\text { I trust my managers and I am confident } \\
\text { that their actions are designed to improve } \\
\text { the life of stakeholders and shareholders. }\end{array}$ & $\begin{array}{c}\text { My managers are only interested in } \\
\text { pursuing their own interest when } \\
\text { designing the company's strategy }\end{array}$ \\
\hline $\begin{array}{c}\text { I trust the company's evaluation tools to } \\
\text { measure my performance. }\end{array}$ & $\begin{array}{c}\text { The evaluation tools are not measuring } \\
\text { accurately my performance within the } \\
\text { company. }\end{array}$ \\
\hline $\begin{array}{c}\text { There is mutual trust between me and my } \\
\text { direct manager. }\end{array}$ & $\begin{array}{c}\text { I can barely trust anything my direct } \\
\text { manager says or does. }\end{array}$ \\
\hline $\begin{array}{c}\text { The trust in my direct manager is based on } \\
\text { analysis of recurrent behaviors that drove } \\
\text { to a high level of confidence and } \\
\text { transparency. }\end{array}$ & $\begin{array}{c}\text { I have blind trust in my direct manager, } \\
\text { because of his/her position. }\end{array}$ \\
\hline
\end{tabular}

Source: Author's own research.

Hypothesis 1a: There is a direct relationship between the trust employees have in their leaders and the organizational performance.

Hypothesis 1b: Having trust in my leaders positively influences my individual performance.

Self -Trust-The ability of the individual to adopt a behavior that matches his/her personal values and principles, by taking advantage of the competencies and capabilities. A trustworthy person will always play upon his integrity and intent, not only on competencies and capabilities.

Table 2. Validating Questions for the Self Trust

The Company is looking both at competencies and capabilities and integrity and intent of its employees.
The Company is focusing exclusively on capabilities and competencies, disregarding completely the integrity of its employees and stakeholders. 


\begin{tabular}{|c|c|}
\hline $\begin{array}{c}\text { I want to be an employee that inspires } \\
\text { trust to my peers, my direct manager and } \\
\text { my upper managers. }\end{array}$ & $\begin{array}{c}\text { I am not interested in demonstrating } \\
\text { trust to any of my peers, direct } \\
\text { manager or upper managers, if I have } \\
\text { great results. }\end{array}$ \\
\hline $\begin{array}{c}\text { I am self-trusted in my ability to set and } \\
\text { meet objectives and goals, keep } \\
\text { commitments and be a role model in my } \\
\text { organization. }\end{array}$ & $\begin{array}{c}\text { I do not focus on keeping commitments } \\
\text { or being a role model for my } \\
\text { organization, I am interested in being } \\
\text { promoted. }\end{array}$ \\
\hline
\end{tabular}

PICBE $\mid 774$

Market Trust- The confidence in the quality and value of the products and services of a company that create the ultimate reputation and image of that company on the market and in the industry served.

The questions that the respondents need to answer is : "I trust that the brands of the company I am working for are designed to improve the life of the consumers." versus " The brands of the company are designed to bring the highest profits to the company, without considering the well-being of the consumers."

Relationship Trust - The perception one has with respect to the individual behavior and how the consistency of this behavior translates into the confidence his peers, colleagues and partners

The relationship trust is tested through the following statements: "There is mutual trust between me and my peers. "and "I can barely trust anything my peers say or do." Hypothesis 1c: Having trust in peers positively influences the individual performance.

Societal Trust-measures the involvement of company in the societal activities and the adjustment of the corporate objectivities to the society needs.

The societal trust is tested through the following statements: "My company is highly involved in social and corporate responsibility activities, because this is part of its core principles and values. " My company is involved in social corporate responsibility activities, because it cares about its image in front of the shareholders and clients.

Hypothesis 1d: Having trust in the company's values and principles, in its products and its contribution for the society helps the individual achieve better results, this hypothesis looking at both market and societal components.

\section{Results}

The results of this preliminary survey are determined, based on the responses of thirtyeight individuals, working in a IT company. As part of extended research, the questionnaire will be applied to other companies from the same sector to validate the hypothesis per which trust acts as a catalyst for one's performance results within an organization.

From a demographic perspective, the distribution of the audience was as following: $66 \%$ male versus $34 \%$ female; $34 \%$ of the individuals are graduates of superior educational programs, $42 \%$ of them followed a post bachelor degree program, while $24 \%$ of them only have a high school diploma. Looking at the seniority in the company, 50\% of the population has been with the company for less than 2 years, 24\% spent between 6 and 10 years with current employer, while 11\% have joined the company more than 11 years ago. When considering the duration of current assignment $24 \%$ of the population spent $2-4$ years in 
the current role, $14 \%$ of them spent between $4-6$ years, while the remaining $58 \%$ have not changed their assignment in the 2 years.

To identify the influence trust has on the individual performance, i used a rate scaling set of seventeen pairs of opposite questions, designed to raise awareness on all the forms that trust can take: self-trust, relationship trust, organizational trust, market trust and societal trust. The rates for each of the 34 questions was measured with a scoring between 1 and 5, where 1 was associated with a "strongly disagree" answer and 5 was granted to all the "strongly agree" answers. The dependent variables in this section of the survey is provided by the individual performance, while the independent variable is the trust of the employees in the principles and values of the company, leaders of the company, peers and evaluation tools used by the company to measure the performance of the employees, as well as confidence in his or her own person.

Out of the 26 validating questions, the top scores were obtained for the ones evaluating the self-trust, closely followed by the relationship trust. The highest score (4.45, out of the maximum 5) highlights that the respondents want to be employees that inspire trust to their peers, direct managers and upper managers, trust being one of the cornerstone for achieving the goals and objectives; the lowest score (1.66) is granted to the question per which the individuals would focus only in gaining as much money as possible, instead of keeping commitments or being a role model for the organizations. This way the scores are logically distributed among pairs of opposite statements, such that the same percentage of population that strongly agrees on the presence of a certain cetgory of trust will strongly disagree on the sentences that support a conflicting behavior.

When analyzing the associated hypotheses related to the impact that trust has on the individual, the scores obtained are the following:

Hypothesis1a: There is a direct relationship between the trust employees have in their leaders and the organizational performance;

$92 \%$ of the interviewed population agrees or strongly agrees that there is a direct relationship between the trust employees have in their leaders and the organizational performance, while only $6 \%$ have no strong opinion towards this assumption.

Hypothesis 1b: The trust an individual has in his/her leaders positively influences his/her individual performance;

$95 \%$ of the respondents agree or strongly agree that the trust in their leaders have a positive influence on their individual performance, while only $5 \%$ see no connection between these dimensions.

Hypothesis 1c: The trust an individual has in his/her peers positively influences his/her individual performance;

$85 \%$ of the interviewed population agree or strongly agree that the trust in their peers have a positive influence in their individual performance, given that the same percentage confirms that there is a mutual level of trust among themselves and their colleagues. $5 \%$ of the respondents don't agree nor disagree with the relationship between these components.

Hypothesis 1d: The trust an individual has in his/her company's values and principles positively influences his/her individual performance.

Among the dimensions that influence the individual performance, the trust in the company's values and principles is perceived as having the lowest impact: only $84 \%$ of the people consider that this organizational trust help them achieve better results in their 
work, while 1 out of 37 respondents disagree with this statement and 5 out of 38 . respondents cannot express any opinion on this hypothesis.

Given the scores obtained for the corresponding validating statements, the entire set of hypotheses appears true and there are strong reasons to argue that the individual trust in the leadership of the company, in the peers and colleagues, organizational values and principles are powerful factors that postively influence the quality of the work and the results achieved by an individual.

\section{Limitation of the research}

The results highlighted in the article, cover only $30 \%$ of the total population, the next step is for the same questionnaire to be extended to the rest of the employees, inside the same company where the current research was conducted. In the same time, the research should also be validated with other companies that activate either in the same business field or they are business partners with the present company, so that a more sustainable conclusion can be withdrawn in the context of mutuality and reciprocity and how this is impacts the business relationships.

One future objective coming from the limitations of this research is to identify instruments that can help measure the impact of trust and of social capital in general on the individual results. Until now the direct relationship between the two variables has been confirmed exclusively through the individual endorsement of each of the corresponding hypotheses addressing different types of trust.

Anther limitation of the research which needs to be addressed is the validation through another research method- either through qualitative or analytic hierarchic process with selected respondents to understand into more details the perception on the positive effect that trust alone, as well as trust in combination with the other dimensions of social capital has both on individual and organizational performance.

\section{Conclusion}

Regardless of the type of trust we are looking at, all the components are perceived and generally recognized as significant differentiators for the individual success and this is also highlighted by the results of the research presented in this paper. All the hypotheses designed to test the direct relationship between the elements of trust and the individual and organizational performance were validated with a score ranging from 4.08 to 4.29 , out of the maximum 5. The interpretation of these results show that more than $84 \%$ of the interviewed population considers that trust helps them solve problems, make decisions faster and eventually help them achieve more competitive results that contribute to the overall performance of the company.

More than the direct impact on the actual results of the individuals, there are some other elements that a company should factor in to understand the indirect influence that trust as component of social capital can have on each stakeholder and their contribution to the prosperity of a firm.

One of those influencers is the innovation and this should be the key for any sustainable performance that each corporation is looking for. The challenge that all leaders of these companies are facing is how to generate theses sources of innovation, such that the products, services and solutions they're selling become top brands in the corresponding 
markets. One of these competitive advantages can be created and supported by the presence of other social capital dimensions, such as shared norms, principles and values, by inspiring trust, confidence in the leadership, organization and the company's values and principles, but also by the care for the community where the company is activating. Another key component that is positively influencing the culture of innovation is the free flow of information and this can only be achieved through networking, bridging and bonding interactions. The networking can be enabled at different levels: interactions among the employees, interactions with different peer companies, part of the same group, interactions with the community, interactions with suppliers, customers, but in the end the outcome can only be a positive one- having access to free information that eventually might translate into innovative ideas, fast decision making, on spot implementation and increase in the customers' satisfaction (Paunescu and Badea, 2013). All these components are translating into active generation of social capital at all levels which will be dealt with in separate research papers.

\section{References}

Adler, Paul S. and Kwon, S.W. (2002) "Social Capital: Prospects for a new concept", Academy of Management Review, Vol. 27, pp. 17-40.

Beattie, R.S. (2006), "Line managers and workplace learning: Learning from the voluntary sector", Human Resource Development International, Vol. 9, No.1, pp. 99-119.

Coleman, J. (1994). "Foundations of Social Theory”, Belknap Press, Cambridge, MA.

Covey, S.R. (2006). "The Speed of Trust", Free Press, New York, pp. 32-40.

Dakhli, M., De Clerq, D. (2004). "Human capital, social capital and innovation: A multicountry study", Entrepreneurship and Regional Development, Vol.16, pp.107-128.

Ellinger, A.D. and Bostrom, R.P. (1999). "Managerial coaching behaviors in learning organizations", Journal of Management Development, Vol. 18, No. 9, pp. 752-771.

Ellinger, A.D.. Ellinger, A.E. and Keller S.B. (2003). "Supervisory coaching behavior, employee satisfaction and warehouse employee performance: A dyadic perspective in the distribution industry", Human Resource Development Quarterly, Vol. 14, No.4, pp. 435-458.

Ellinger, A.E., Elmadag, A.B. and Ellinger, A.D. (2007). "An examination of organizations' frontline service employee development practices", Human Resource Development Quarterly, Vol. 18, No.3.], pp. 293-314.

Elmadag, A.B., Ellinger, A.E. and Franke, G.R. (2008). "Antecedents and consequences of frontline service employee commitment to service quality", Journal of Marketing Theory and Practice, Vo. 16, No.2, pp. 95-110.

Ellinger, A.E, Ketchen D.J., Hult, GTL, Elmadag, AB and Richey RG Jr. (2008). "Marketorientation, employee development practices and performance", Industrial Marketing Management, Vol. 37, No4., pp 353-366.

Ghoshal, S. \& Barlett, C. (1995). "Changing the role of top management: Beyond structure to processes", Harvard Business Review, Vol.73, No.1, pp 86-96.

Hazelton, V., Kennan, W. (2000). "Social Capital: reconceptualising the bottom line", Corporate Communications, Vol.5, No.2, pp 81-96.

Jones, I., Nyland, C., Pollitt, M. (2001). "How do Multinational Build Social Capital? Evidence from South Africa", ESRC Centre for Business research, University of Cambridge. 
Nahapiet, J., Ghoshal, S. (1998). "Social capital, intellectual capital and the organizational advantage", Academy of Management Review, Vol. 23, No.3, pp. 242-266.

Paunescu, C, Badea, M.R. (2013). "Social Capital Frameworks and its influence on the entrepreneurial activity", The Annals of University of Oradea, Oradea, pp. 581-589.

Putnam, R.D. (2000). "Bowling Alone: The Collapse and Revival of American Community", New Tork, Simon\& Schuster.

PICBE | 778

Shane, S.A. (2004). "A General Theory of Entrepreneurship: The Individual-opportunity Nexus", Cheltenham, U.K.: Edward Elgar.

Starck, K., Kruckeberg, D. (2003). "Ethical obligations of public relations in an era of globalization", Journal of Communication Management, Vol. 8, No 1, pp. 29-40.

Tsai, W., Ghoshal, S. (1998). "Social capital and value creation: the role of intrafirm networks", Academy of Management Journal, Vol. 42, No. 4, pp. 464-476. 